\title{
EFFECT OF PHYSICAL ACTIVITY IN TREATMENT OF PAEDIATRIC OBESITY
}

\author{
Dalibor Pastucha ${ }^{1,3}$, Jana Malinčíková2, Stanislav Horák ${ }^{2}$, Jana Povová1, Petr Konečný4 \\ 'Department of Epidemiology and Public Health, Faculty of Medicine, University of Ostrava, Ostrava, Czech Republic \\ ${ }^{2}$ Department of Exercise Medicine and Cardiovascular Rehabilitation, University Hospital Olomouc and Faculty of Medicine and Dentistry, \\ Palacký University Olomouc, Olomouc, Czech Republic \\ ${ }^{3}$ Department of Rehabilitation, Faculty of Medicine, University of Ostrava, Ostrava, Czech Republic \\ ${ }^{4}$ International Clinical Research Centre Hospital of St. Anna and Medical Faculty of Masaryk University, Brno, Czech Republic
}

\begin{abstract}
SUMMARY
The aim of the study was to compare the differences in anthropometric parameters, maximal oxygen uptake $\left(\mathrm{VO}_{2} \mathrm{max}\right)$ and physical activity (PA) between groups of 146 obese boys and 128 obese girls. We tried to describe the relationships between changes in PA and changes in $\mathrm{VO}_{2}$ max, body fat, weight, waist circumference and hip circumference. We found statistically significant changes in $\mathrm{VO}_{2}$ max and waist circumference only in the group of boys and significant changes in $\mathrm{VO}_{2}$ max in the group of girls.
\end{abstract}

Key words: obesity, physical activity, anthropometric parameters, children

Address for correspondence: D. Pastucha, Department of Epidemiology and Public Health, Faculty of Medicine, University of Ostrava, Syllabova 19, 70300 Ostrava, Czech Republic. E-mail: DPastucha@email.cz

\section{INTRODUCTION}

Physical activity is critical to the healthy development of children. The percentage of compliance with moderate-to-vigorous physical activity (MVPA) recommendations for European children varies considerably between the sexes and countries, and is generally low with similar trends in boys and girls. This may have important implications for public health policy and PA counselling (1). In the Czech Republic, paediatric obesity is a serious epidemiological problem, with $20 \%$ of children aged $6-12$ years and $11 \%$ of those aged $13-17$ years being already overweight or obese. These data were provided by the 2005 Czech Society for the Study of Obesity Association survey entitled Lifestyle and Obesity. The Czech paediatric population was divided into two age groups, 6-12 years and 13-17 years. In the former group, $10 \%$ of children were overweight and $10 \%$ were obese. The highest proportion of children suffering from obesity (18\%) was found among those aged 7 years, which is close to the time they start attending school and their lifestyle changes. The data for adolescents, on the other hand, are more favourable: the proportion of overweight children aged 13-17 years dropped to $6 \%$, and $5 \%$ of them were obese (2). Simple obesity frequently occurs on a polygenic basis as a typical lifestyle disorder in developed countries of the world. It is characterized by the gradual onset and development of typical complex metabolic changes. A unifying element of genetic polymorphisms is the loss of physiological regulatory mechanisms and the prevalence of accumulation mechanisms for energy conservation. Adipose tissue is the largest endocrine organ in the human body, and when its excessive multiplication occurs, gradual but extensive metabolic changes take place (3). In the case of chronic metabolic consequences, the most active is the visceral adipose tissue, which has the most significant share in the development of relative hypercortisolism, hyperestrogenism, insulin resistance and hypercoagulation. This chronic condition, that can last for decades, is potentiated by prolonged failure of the pancreatic $\beta$-cells and proatherogenic and pro-immunosuppressive conditions. Complex metabolic changes, acting in a mutually linked manner, are the basic cornerstones of metabolic syndrome development.

\section{MATERIALS AND METHODS}

A total of 274 children with a median age of 12 years (range 9-17 years) were enrolled in the study. These children have been monitored in the Obesity Centre of the Department of Exercise Medicine and Cardiovascular Rehabilitation, University Hospital Olomouc and Faculty of Medicine and Dentistry, Palacký University in Olomouc. The group comprised 146 boys and 128 girls. The children were referred to the centre by their paediatricians to reduce their abnormal body weight. Given the objective of the study, only children with a body mass index (BMI) above the 97th percentile were included. All children underwent combined spirometry (Oxycon Champion, Jaeger) and ergometry (Sana Bike, Ergosana) tests. For each child, the following parameters were determined: blood pressure, measured with a standard mercury sphygmomanometer using a stethoscope placed over the brachial artery for listening to the pulse in accordance with the Task Force Report on High Blood Pressure in Children and Adolescents waist circumference, measured at a level midway between the lowest rib and the iliac crest; and hip circumferences, measured at the widest part of the hip. 


\section{Statistics}

For data analysis, the software Statistica 8 (StatSoft, Inc.) was used. Comparative analysis between the groups was carried out using the Mann-Whitney test; Spearman's correlation coefficient was used when considering correlation with age. The level of significance was set at $\mathrm{p}<0.05$.

\section{RESULTS}

Tables 1 and 2 show the results of tests in the groups of obese boys and girls, namely the mean and standard deviation, median, minimum and maximum values of the parameter in the group and the 25th and 75th percentiles.

Physical fitness of obese children was evaluated based on spirometry determining maximal oxygen uptake $\left(\mathrm{VO}_{2} \max \right)$ values. In all boys and girls, the values were significantly below normal for age and sex.

The last endpoint was physical activity (PA) calculated in minutes per week. Data on the amount of PA were only ascertained from children and their parents and were not objectively evaluated using a pedometer or accelerometer. Physical activity included physical education at school and sports activities in the children's leisure time. The mean time of PA in the group of boys was $179.88 \mathrm{~min} /$ week with a median of $150 \mathrm{~min} /$ week. Two boys were exempted from physical education at school and reported no physical activity. In the group of girls, mean physical activity was $133.42 \mathrm{~min} /$ week with a median of $90 \mathrm{~min} /$ week. Three girls reported no physical activity and did not even participate in physical education at school.

From the total of 146 boys and 128 girls enrolled in the study, only 130 boys and 108 girls participated in the process of losing weight through physical activity and dietary measures. All participants were offered consultation with a nutritional therapist who educated both children and persons responsible for preparing food in the family. The dietary recommendations were not only aimed at containing obesity but also comorbidities (hypertension, dyslipidemia, etc.). To determine basal metabolism, bioimpedance analysis was performed with the Bodystat system.

Based on the spiroergometric examination, the $\mathrm{VO}_{2}$ max values were determined and the children were recommended physical activity at a pulse rate in the range of $50-60 \%$ of $\mathrm{VO}_{2} \max$. The children were advised to gradually increase their PA to 40-60 minutes, 3-5 times per week, preferably every other day. The participants visited our centre for check-ups regularly at 3-week intervals. After 6 months, the effect of changes in PA on the anthropometric parameters and physical fitness were evaluated. The results were compared with baseline values prior to the intervention. The analyses of paired observations were made using the Wilcoxon paired test (Table 3).

Table 1. The clinical characteristics of the studied population of boys

\begin{tabular}{|l|c|c|c|c|c|c|c|}
\hline $\mathrm{n}=146$ & mean & median & $\min$ & $\max$ & 25th percentile & 75th percentile & SD \\
\hline Weight (kg) & 79.41 & 77.3 & 45.5 & 131.7 & 63.9 & 98.2 & 22.23 \\
\hline Body fat (\%) & 30.35 & 31.8 & 18 & 42.2 & 27.5 & 34 & 5.48 \\
\hline VO $_{2} \max (\mathrm{ml} / \mathrm{kg} / \mathrm{min})$ & 30.74 & 30.5 & 20 & 43 & 27 & 33.7 & 6.33 \\
\hline Waist (cm) & 94.28 & 93 & 75 & 134 & 84.5 & 103 & 12.54 \\
\hline Hip (cm) & 101.15 & 101 & 80 & 129 & 91 & 107 & 12.22 \\
\hline Physical activity (min/week) & 179.88 & 150 & 0 & 450 & 90 & 270 & 104.74 \\
\hline Age (years) & 13.29 & 13 & 9.5 & 17 & 11.5 & 15 & 2.34 \\
\hline
\end{tabular}

Table 2. The clinical characteristics of the studied population of girls

\begin{tabular}{|l|c|c|c|c|c|c|c|}
\hline $\mathrm{n}=\mathbf{1 2 8}$ & mean & median & $\min$ & $\max$ & 25th percentile & 75th percentile & SD \\
\hline Weight (kg) & 67.50 & 65.2 & 31.5 & 124.2 & 51.2 & 81.6 & 20.99 \\
\hline Body fat (\%) & 31.85 & 32 & 18 & 48.5 & 27.3 & 35.9 & 7.26 \\
\hline VO $\max (\mathrm{ml} / \mathrm{kg} / \mathrm{min})$ & 27.64 & 28.4 & 8.9 & 38.3 & 24.8 & 30.6 & 6.01 \\
\hline Waist (cm) & 83.93 & 80 & 65 & 119 & 75 & 92 & 13.01 \\
\hline Hip (cm) & 96.51 & 96 & 73 & 145 & 83 & 107 & 15.48 \\
\hline Physical activity (min/week) & 133.42 & 90 & 0 & 320 & 90 & 210 & 83.06 \\
\hline Age (years) & 12.55 & 11.5 & 9.1 & 17.5 & 10.2 & 14.2 & 2.72 \\
\hline
\end{tabular}

Table 3. P-values of changes after 6 months

\begin{tabular}{|l|c|c|c|c|c|c|}
\hline & weight $(\mathrm{kg})$ & body fat $(\%)$ & $\begin{array}{c}\mathrm{VO}_{2} \max \\
(\mathrm{m} / \mathrm{kg} / \mathrm{min})\end{array}$ & waist (cm) & hip (cm) & $\begin{array}{c}\text { physical activity } \\
(\mathrm{min} / \text { week }\end{array}$ \\
\hline $\begin{array}{l}\text { Boys } \\
n=130\end{array}$ & 0.19824 & 0.16639 & 0.00028 & 0.02775 & 0.38784 & 0.00003 \\
\hline $\begin{array}{l}\text { Girls } \\
n=108\end{array}$ & 0.86645 & 0.45934 & 0.00012 & 0.60261 & 0.07157 & 0.00001 \\
\hline
\end{tabular}




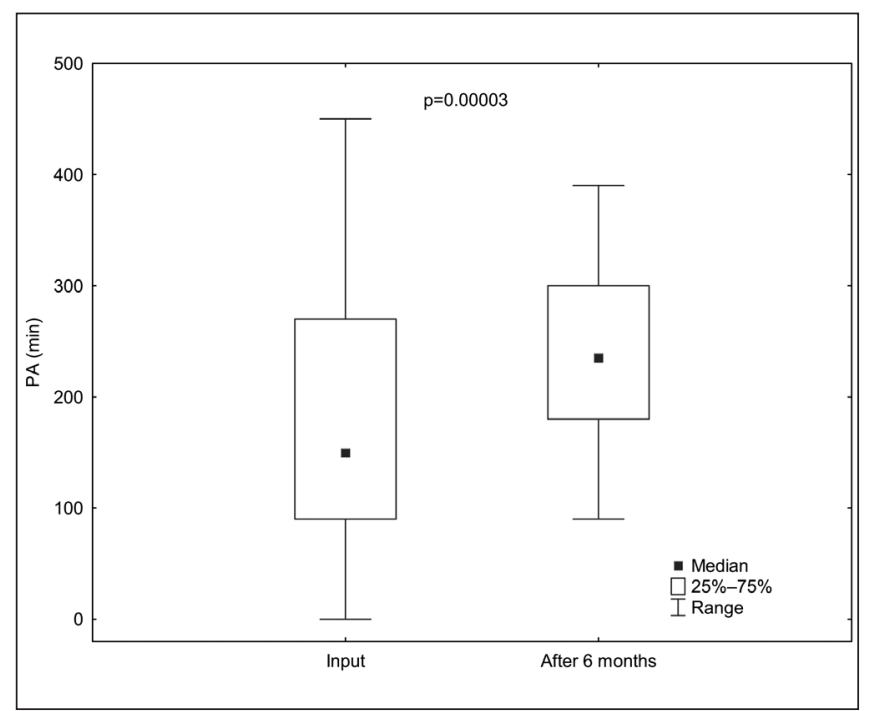

Fig. 1. Physical activity of boys.

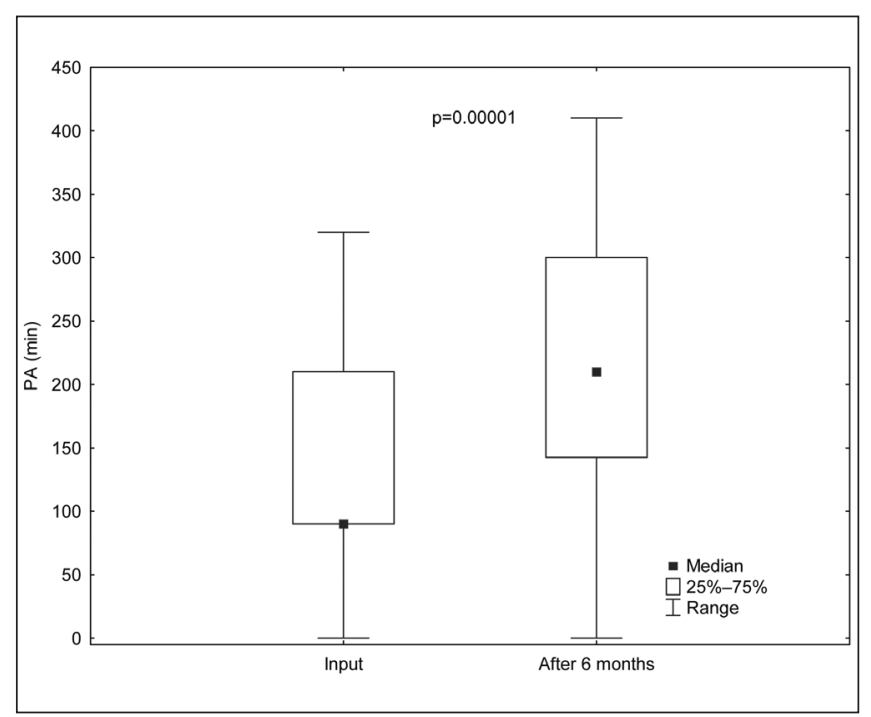

Fig. 2. Physical activity of girls.

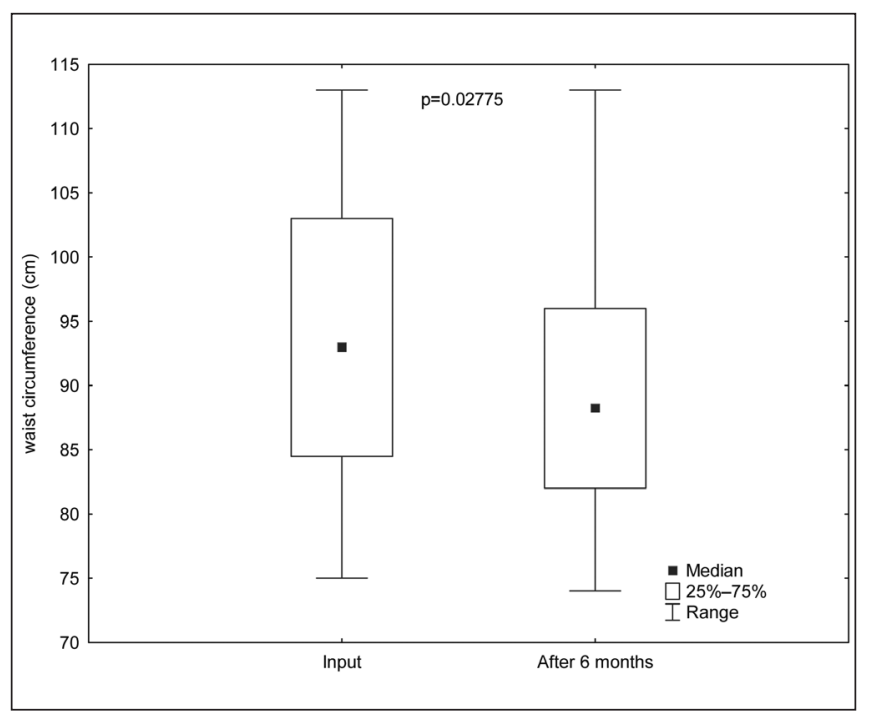

Fig. 3. Waist circumference of boys.
The analyses showed significant increases in $\mathrm{VO}_{2}$ max values in both group of boys $(p=0.00028)$ and girls $(p=0.00012)$. Both groups also showed significant increases in the total amount of PA. The p-values were 0.00003 (Fig. 1) and 0.00001 (Fig. 2) for boys and girls, respectively. The reduction in waist circumference was only found in the group of boys $(p=0.02775)$ (Fig. 3); in the group of girls, this parameter has not changed significantly. Changes in other monitored parameters (weight, amount of fat mass and hip circumference) did not reach statistical significance.

\section{DISCUSSION}

The objective of the present study was to investigate a group of obese children. Based on comprehensive clinical examination, anthropometric measurements and spiroergometric examination, non-pharmacological interventions were initiated, aimed specifically at lifestyle changes and not just changing eating habits, with particular emphasis on PA. The main objectives were to determine the correlations between the change in PA and changes in basic anthropometric parameters and cardiovascular exercise tolerance, and to assess whether regular MVPA has a significant impact on the children's weight, body fat, waist and hip circumferences and $\mathrm{VO}_{2}$ max. Based on these findings, the most appropriate PA for obese children should be proposed, with regard to possible adverse effects on the musculoskeletal system of the growing child and the general limits of PA prescription in childhood.

Very often, obesity has been associated with a lack of PA and sedentary lifestyle (4). The present comparison of PA in obese boys and girls demonstrated a significant difference in the amount of PA per week. Girls had significantly less physical activity than boys $(\mathrm{p}<0.05)$. The mean time of PA in boys was $179.88 \mathrm{~min} /$ week with a median of $150 \mathrm{~min} /$ week. Two boys were exempted from physical education at school and reported no physical activity. In the group of girls, the mean physical activity was 133.42 $\mathrm{min} /$ week with a median of $90 \mathrm{~min} /$ week. Three girls reported no physical activity and did not even participate in physical education at school. This is in contrast with, for instance, recommendations from the American Heart Association stating that children aged 5 years and older should spend at least 30 minutes a day doing moderate-intensity PA and more intense PA should be performed for at least 30 minutes, three times a week. The usual recommended duration and intensity of PA suggest 45-60 minutes, 3-4 times a week, at least every other day, at a level of $50-70 \%$ of $\mathrm{VO}_{2} \max (5)$.

Only 77 boys and 54 girls reached the above recommended intensity and frequency. For most of the obese children, the only PA comprised physical education classes at school; that is, 45 minutes 2-3 times a week. The students' overall motivation for PA is low. The alarming lack of physical activity in children's leisure time outside school physical education was also reported by Kárníková and Vaníčková claiming that regular extracurricular PA performed by fewer than $50 \%$ of children suggested an exercise regimen crisis (6). Similar conclusions were made by a number of other authors $(7,8)$. The difference in PA between boys and girls was also reported by other authors such as Goldfield et al. The main advantage of the study was objective PA monitoring with an accelerometer. The disadvantage was a significantly smaller group of probands (30 obese or overweight children) $(9,10)$. A similar 
difference in PA between boys and girls in a much larger group was found by Farpour-Lambert et al. They also demonstrated correlations between an increase in PA and reduced body fat, lower sleep blood pressure and increased $\mathrm{VO}_{2} \max (11)$. Jabbour et al. found that 30 minutes or more of MVPA per day were associated with a potentiation of aerobic fitness indicators in obese prepubertal children. Moreover, the indices of aerobic fitness of inactive obese children were significantly different from those of active obese and non-obese ones (12).

A statistically significant correlation between absolute change in $\mathrm{PA}$ and higher $\mathrm{VO}_{2}$ max was demonstrated in the present group of obese boys; in the group of girls, the association was not statistically significant. Using Spearman's correlation coefficient, we assessed the relationship between the change in $\mathrm{PA}$ and $\mathrm{VO}_{2}$ max $(\mathrm{mL} / \mathrm{kg} / \mathrm{min})$ and between the percentage change in PA and the above parameter. Changes in PA also correlated with changes in some of the anthropometric parameters. In boys, there was a statistically significant correlation not only between percentage change but also absolute change in time of PA and changes in waist and hip circumferences and in weight. The greater percentage increase in PA, the smaller hip circumference $(p<0.001)$ and also the smaller waist circumference $(p<0.001)$. The greater percentage increase in PA, the greater weight decrease $(p<0.001)$. For girls, the only statistically significant correlation was between percentage change in time of PA and change in hip circumference $(p<0.01)$. Studies on PA, physical fitness and anthropometric parameters in both healthy people and obese individuals showed different results regarding the correlations and the effect of exercise therapy on these indicators. These studies showed large interindividual differences among obese participants. In the adult population, the effect of PA on anthropometric as well as physical fitness parameters was reported in a number of studies less often, however, the paediatric population was studied. Some authors such as Vizinová et al. or Tolfrey et al. failed to prove this significant increase in $\mathrm{VO}_{2} \max$ after an 8-week programme of controlled exercise $(7,12-18)$.

The absolute amount of physical activity associated with positive changes in anthropometric parameters was very individual. Thus, it is impossible to recommend a uniform amount of PA that would lead to reduction in weight or body fat based on our observations. Similar results were published, for instance, by Okay et al. (19). Therefore, we compared the changes in both absolute duration of PA and percentage change in PA and its correlation with the selected factors. In the group of girls, there was no significant correlation with the absolute change of PA, which was probably insufficient, but there was a statistically significant correlation between percentage change in PA and the change in hip circumference $(19,20)$.

\section{CONCLUSION}

In the group of obese boys, statistically significant correlations were found between the change in PA and the monitored anthropometric parameters (weight, body fat, waist and hip circumference); changes in these parameters in girls were not statistically significant. After 6-month non-pharmacological intervention, there was a statistically significant change in $\mathrm{PA}$ and $\mathrm{VO}_{2}$ max in both sexes. In the group of boys, there was also a statistically significant reduction in waist circumference. These results may be useful in the design of strategies and programmes to increase physical activity levels in order to achieve better health. Physically active children have significantly better cardiorespiratory fitness levels than inactive children.

\section{Conflict of Interest}

None declared

\section{REFERENCES}

1. Konstabel K, Veidebaum T, Verbestel V, Moreno LA, Bammann K, Tornaritis $\mathrm{M}$, et al.; IDEFICS consortium. Objectively measured physical activity in European children: the IDEFICS study. Int J Obes (Lond). 2014 Sep;38 Suppl 2:S135-43.

2. Vígnerová J, Riedlová J, Bláha P, Kobzová J, Krejčovský L, Brabec M, et al. 6th Nation-wide anthropological survey of children and adolescents 2001, Czech Republic: summary results. Prague: Charles University in Prague; 2006.

3. Pastucha D, Filipčíková R, Horáková D, Azeem K, Malinčíková J, Kocvrlich M. Evaluation of insulin resistance and metabolic syndrome in a group of obese Czech children. J Pediatr Endocrinol Metab. 2014 Jul;27(7-8):651-6.

4. Bukara-Radujković G, Zdravković D. Physical activity as an important determinant in developing childhood obesity. Med Pregl. 2009 MarApr;62(3-4):107-13.

5. Kytnarová J, Aldhood-Hainerová I, Boženský J, et al. Obesity in children. In: Standards of therapeutical procedures and quality in health care: manual of increasing the quality of health care for hospitals, policlinics, practitioners, and specialists. Prague: Dashofer; 2011. p. 6-11. (In Czech.)

6. Kárníková R, Vaníčková E. Physical activity in school children. Med Sport Boh Slov. 1992;1(4):20-25. (In Czech.)

7. Máček M, Matouš M. The importance of exercise and physical activity in the treatment and prevention of hypertension. Med Sport Boh Slov. 2001;10(3):113-9. (In Czech.)

8. Kučera M, et al. Physical activity in prevention and therapy: chapters from sports medicine for students of physiotherapy. Prague: Karolinum; 1996. (In Czech.)

9. Goldfield GS. Predictors of response to an intervention modifying physical activity and sedentary behavior in overweight/obese children: attitudes vs. behavior. J Phys Act Health. 2009 Jul;6(4):463-6.

10. Goldfield GS, Mallory R, Prud'homme D, Adamo KB. Gender differences in response to a physical activity intervention in overweight and obese children. J Phys Act Health. 2008 Jul;5(4):592-606.

11. Farpour-Lambert NJ, Aggoun Y, Marchand LM, Martin XE, Herrmann FR, Beghetti M. Physical activity reduces systemic blood pressure and improves early markers of atherosclerosis in pre-pubertal obese children. J Am Coll Cardiol. 2009 Dec 15;54(25):2396-406.

12. Jabbour G, Henderson M, Tremblay A, Mathieu ME. Aerobic fitness indices of children differed not by body weight status but by level of engagement in physical activity. J Phys Act Health. 2015 Jun;12(6):85460 .

13. McMurray RG, Bauman MJ, Harrell JS, Brown S, Bangdiwala SI. Effects of improvement in aerobic power on resting insulin and glucose concentrations in children. Eur J Appl Physiol. 2000 Jan;81(1-2):132-9.

14. Bouchard C, Rankinen T. Individual differences in response to regular physical activity. Med Sci Sports Exerc. 2001 Jun;33(6 Suppl):S446-51.

15. Fortier MD, Katzmarzyk PT, Bouchard C. Physical activity, aerobic fitness, and seven-year changes in adiposity in the Canadian population. Can J Appl Physiol. 2002 Oct;27(5):449-62.

16. Skinner JS, Gaskill SE, Rankinen T, Leon AS, Rao DC, Wilmore JH, et al. Heart rate versus \%VO2max: age, sex, race, initial fitness, and training response-HERITAGE. Med Sci Sports Exerc. 2003 Nov;35(11):1908-13.

17. Vizinová H, Malinčíková J, Wiedermann J. Effects of endurance training on clinical, metabolic and cardiorespiratory profile of children and adolescents with essential hypertension. Med Sport Boh Slov. 2002;11(4):280-6. (In Czech.) 
18. Tolfrey K, Goosey-Tolfrey VL, Campbell IG. Oxygen uptake-heart rate relationship in élite wheelchair racers. Eur J Appl Physiol. 2001 Dec;86(2):174-8.

19. Okay DM, Jackson PV, Marcinkiewicz M, Papino MN. Exercise and obesity. Prim Care. 2009 Jun;36(2):379-93.

20. Pastucha D, Filipčíková R, Horáková D, Radová L, Marinov Z, Malinčíková J, et al. The incidence of metabolic syndrome in obese
Czech children: the importance of early detection of insulin resistance using homeostatic indexes HOMA-IR and QUICKI. Physiol Res. 2013 Jul 18;62(3):277-83

Received November 15, 2014 Accepted in revised form March 25, 2015 